\title{
Modified ultrafiltration \& postoperative course in patients undergoing repair of Tetralogy of Fallot
}

\author{
Sachin Talwar ${ }^{1}$, Neralakere Sujith ${ }^{1}$, Palleti Rajashekar ${ }^{2}$, Neeti Makhija ${ }^{1}$, Vishnubhatla \\ Sreenivas $^{1}$, Ashish Upadhaya ${ }^{1}$, Manoj Kumar Sahu ${ }^{3}$, and Shiv Choudhary ${ }^{4}$ \\ ${ }^{1}$ All India Institute of Medical Sciences \\ ${ }^{2}$ All India Institute of Medical Sciences, Cardiothoracic \& Vascular Surgery New Delhi, \\ India \\ ${ }^{3}$ All India Inst Med Sci \\ ${ }^{4}$ Affiliation not available
}

November 13, 2020

\begin{abstract}
Background: Expected benefits of modified ultrafiltration(MUF) include increased hematocrit, reduction of total body water \& inflammatory mediators, improved left ventricular systolic function, \& improved systolic blood pressure and cardiac index following cardiopulmonary bypass(CPB). This prospective randomized trial tested this hypothesis. Methods: 79 patients undergoing intracardiac repair of Tetralogy of Fallot(TOF) were randomized to MUF group(Group-M, n=39) or only conventional ultrafiltration(CUF) group(Group-C, $\mathrm{n}=40)$. Primary outcome was change in hematocrit. Secondary outcomes were changes in peak airway pressures, ventilatory support, blood transfusions, time to peripheral rewarming, mean arterial pressure, central venous pressure, inotrope score(IS) and cardiac index. Serum inflammatory markers were measured. Results: Following MUF, Group-M had higher hematocrit(44.3 $\pm 0.98 \mathrm{~g} / \mathrm{dl})$ compared to Group- $\mathrm{C}(37.8 \pm 1.37 \mathrm{~g} / \mathrm{dl}), \mathrm{P}=<0.001$. Central venous pressure $(\mathrm{mmHg})$ immediately following sternal closure was $9.27 \pm 3.12 \mathrm{mmHg}$ in Group-M \& $10.52 \pm 2.2 \mathrm{mmHg}$ in $\mathrm{Group}-\mathrm{C}(\mathrm{P}=0.04)$. In the ICU, they were $11.52 \pm 2.20 \mathrm{mmHg}$ in Group-C and $10.84 \pm 2.78 \mathrm{mmHg}$ in Group- $\mathrm{M}(\mathrm{P}=0.02)$. Time to peripheral rewarming was $6.30 \pm 3.91$ hours in Group-M and $13.67 \pm 3.91$ hours in Group- $\mathrm{C}(\mathrm{P}=0.06)$. Peak airway pressures in ICU were $17 \pm 2 \mathrm{mmHg}$ in Group-M \& 20.55 $\pm 2.97 \mathrm{mmHg}$ in Group-C, $\mathrm{P}<0.001$. Duration of mechanical ventilation was $6.3 \pm 2.7$ hours in Group-M compared to $14.7 \pm 3.5$ hours in Group- $\mathrm{C}(\mathrm{P}=0.002)$. IS was $11.52 \pm 2.20$ in Group-C compared to $10.84 \pm 2.78$ in Group-M. 8/39(20.5\%) patients in Group-M had IS $>10$ compared to $22 / 40(55 \%)$ patients in Group- $\mathrm{C}(\mathrm{P}=0.02)$. Serum Troponin- $\mathrm{T}$ and Interleukin6 levels were lower in Group-M; TNF- $\alpha$ and CPK-MB were similar. ICU \& hospital stay were similar. Conclusion: MUF group had higher post-operative hematocrit, decreased duration of mechanical ventilation, lower need for inotropes \& lower Interleukin-6 \& Troponin-T levels. MUF group had better post-operative outcomes.
\end{abstract}

\section{Hosted file}

JOCS SUBMITTED.pdf available at https://authorea.com/users/375506/articles/492722-modifiedultrafiltration-postoperative-course-in-patients-undergoing-repair-of-tetralogy-offallot 